\title{
Renovação estética na música do Rio Grande do Sul entre as décadas de 1920 e 1940: iniciativas pontuais ou um movimento articulado?
}

\section{Gustavo Frosi Benetti}

Resumo: Pretende-se discutir, por meio deste artigo, o processo de renovação estética na música sul-rio-grandense entre as décadas de 1920 e 1940, representado pelos compositores Armando Albuquerque, Radamés Gnattali, Luiz Cosme e Natho Henn. Para tanto, compõem o referencial pesquisado escritos dos compositores investigados, de estudiosos da época em questão e também de críticos posteriores. Observou-se indícios de articulação dos referidos compositores em torno de ideais estéticos comuns, e também um alinhamento ao âmbito literário correspondente.

Abstract: I intend to discuss, through this article, the process of aesthetic renewal in Rio Grande do Sul music from the 1920s to 1940s, represented by the composers Armando Albuquerque, Radamés Gnattali, Luiz Cosme and Natho Henn. Therefore, the bibliography researched consists on writings of the investigated composers, contemporary scholars and later critics. There are evidences of articulation of this composers in common aesthetic ideals, and also an alignment to the corresponding literary context.

\section{Percurso da música de concerto sul-rio-grandense}

A trajetória da composição musical artística no Rio Grande do Sul (RS) é mais recente do que a de outros estados, especialmente os das regiões Nordeste e Sudeste. Em virtude da escassez de registros, sabese pouco sobre o cenário musical sul-rio-grandense anterior ao século XIX. Durante o século XVIII estados como Rio de Janeiro, São Paulo, Minas Gerais, Bahia e Pernambuco já demonstravam atividade musical intensa. Para Antônio Corte Real, isto se justifica pelas seguintes razões: 
A situação geográfica do Estado do Rio Grande do Sul, que o insulou em parte das demais unidades da Federação, até que se conquistassem eficientes meios de comunicação; as circunstâncias peculiares de seu povoamento, particularmente no que diz respeito ao fluxo migratório de origem alemã e italiana; suas condições políticas que, por longo tempo o mantiveram em constante estado de beligerância, já por motivos políticos de ordem interna, já por motivos de delimitações de fronteiras, constituem fatores que, do ponto de vista histórico-social e estético, exigem ser considerados singularmente para que se não falseie o relato do ambiente em que se processou o cultivo da música em terras gaúchas (Corte Real, 1980, p. 11).

Os primeiros registros de algum movimento significativo no que diz respeito à música, no estado, datam dos anos posteriores à Independência. A partir de um dos encontros bélicos da Revolução Farroupilha (1835-1845), no ano de 1838, se estabeleceria no estado o mestre de música Joaquim José de Mendanha (Ouro Preto, 179[8?] Porto Alegre, 1885), um dos capturados na batalha. O Hino Republicano Rio-Grandense, única obra sua de autoria reconhecida, viria a ser oficializado como o Hino Rio-Grandense no ano 1966. O nome de Joaquim José de Mendanha ficou para a posteridade não como um compositor representativo, mas como precursor na música da capital. A Sociedade de Música de Porto Alegre, fundada por ele em 1855, foi a primeira do estado, cuja orquestra teria tocado na inauguração do Theatro São Pedro em 1858 (Ferreira, 1956, p. 54).

A partir das últimas duas décadas do século $\mathrm{XIX}$, o progresso urbano de Porto Alegre impulsionaria o desenvolvimento de atividades artísticas e culturais. Formaram-se sociedades com a finalidade de promover concertos e de viabilizar o ensino da música. Em 1878 foi fundada a Sociedade Filarmônica Porto-Alegrense. Em Pelotas, data do ano de 1892 a criação do Clube Beethoven - extinto em 1898, e de 1894 a Orquestra Filarmônica Pelotense. As duas entidades dispunham de orquestra e de coro (Nogueira, 2003, p. 109-112). Alguns anos depois 
de extinta a Sociedade Filarmônica Porto-Alegrense, em 1896, fundouse o Instituto Musical Porto-Alegrense. Todas as instituições possuíam um direcionamento artístico similar, com repertórios baseados nas escolas europeias - períodos do classicismo e do romantismo.

Até os anos 1920, poucos músicos contribuíram para a história da composição musical no estado. Dentre esses, destacaram-se os primos José de Araujo Vianna e Murillo Furtado, nascidos na década de 1870. Ambos compunham em uma estética operística italiana. Sem uma escola, outros músicos rio-grandenses buscaram como alternativa a sua formação no Instituto Nacional de Música, no Rio de Janeiro, e não mais atuaram no estado, como João Otaviano Gonçalves (1892-1916), Antônio de Assis Republicano (1897-1960) e Joanídia Nuñes Sodré (1903-1975).

Somente no ano de 1908 surgiria no estado a primeira instituição voltada ao ensino das artes, o Instituto Livre de Belas Artes. Dentre os fundadores, destaca-se o nome de Araujo Vianna. O Conservatório de Música, seção do instituto, entrou em funcionamento em 1909. Na década de 1940 o Instituto viria a ser incorporado à Universidade do Rio Grande do Sul, posteriormente denominada Universidade Federal do Rio Grande do Sul (UFRCS), da qual faz parte até hoje. Entre os primeiros professores do Conservatório de Música figuravam os nomes dos compositores rio-grandenses Araujo Vianna, Murillo Furtado e João Schwarz Filho. Em 1916 a direção foi assumida por Guilherme Fontainha que idealizou "um projeto de interiorização da cultura artística, com o objetivo de criar na província um movimento musical autônomo, independente do Rio de Janeiro" (Nogueira; Souza, 2007, p. 345). Entre as cidades incluídas no projeto estavam Pelotas, Rio Grande, Santana do Livramento, Bagé, Cachoeira do Sul e Caxias do Sul. Apesar disso, a composição musical dos primeiros anos do século XX, no estado, concentrou-se em Porto Alegre e tinha como principais influências o classicismo e o romantismo musical europeu, com características marcadamente tonais. Os poucos compositores em atividade na época 
estiveram em algum momento ligados ao Conservatório de Música do Instituto de Belas Artes do Rio Grande do Sul.

\section{A renovação estética a partir dos anos 1920}

Durante a década de 1920, a música erudita brasileira passava por um processo de transformação, e no RS não foi diferente. A década em questão produziu importantes compositores, cujas obras tornaramse referências e objetos de estudo para as gerações posteriores. Em 1922, ano da Semana de Arte Moderna, os poucos compositores sul-riograndenses em atividade ainda apresentavam obras tradicionais, em linguagem tonal clássica ou romântica. Quatro anos depois, em 1926, Armando Albuquerque (Porto Alegre, 1901 - 1986) compôs Pathé-Baby, para piano. Essa obra, apesar de apresentar uma estrutura harmônica predominantemente tonal, incorpora elementos tipicamente modernos, como passagens modais e métrica irregular. Entre os compositores sulrio-grandenses, Armando ocupa um lugar importante, sua obra é numerosa e expressiva. Compôs para orquestra, música de câmara, música vocal e para piano. Pode ser considerado o primeiro compositor rio-grandense a romper com a barreira do tonalismo e experimentar tendências de vanguarda. Para Gilberto Mendes, Armando Albuquerque:

[...] captou as verdadeiras vibrações de seu tempo e ele chegou, por intuição, a uma obra que refletiu sozinha, no Brasil, lá no Sul, o expressionismo popularesco de um Kurt Weil, de um George Antheil, compositores que provavelmente ele nem conhecia naquele tempo (1928). Até nos títulos a gente sente a atmosfera daquela época, daquela geração maldita que viveu entre Paris e Berlim prénazista, a Berlim do cabaret (apud Mariz, 2005, p. 220). 
Figura 1: Pathé-Baby
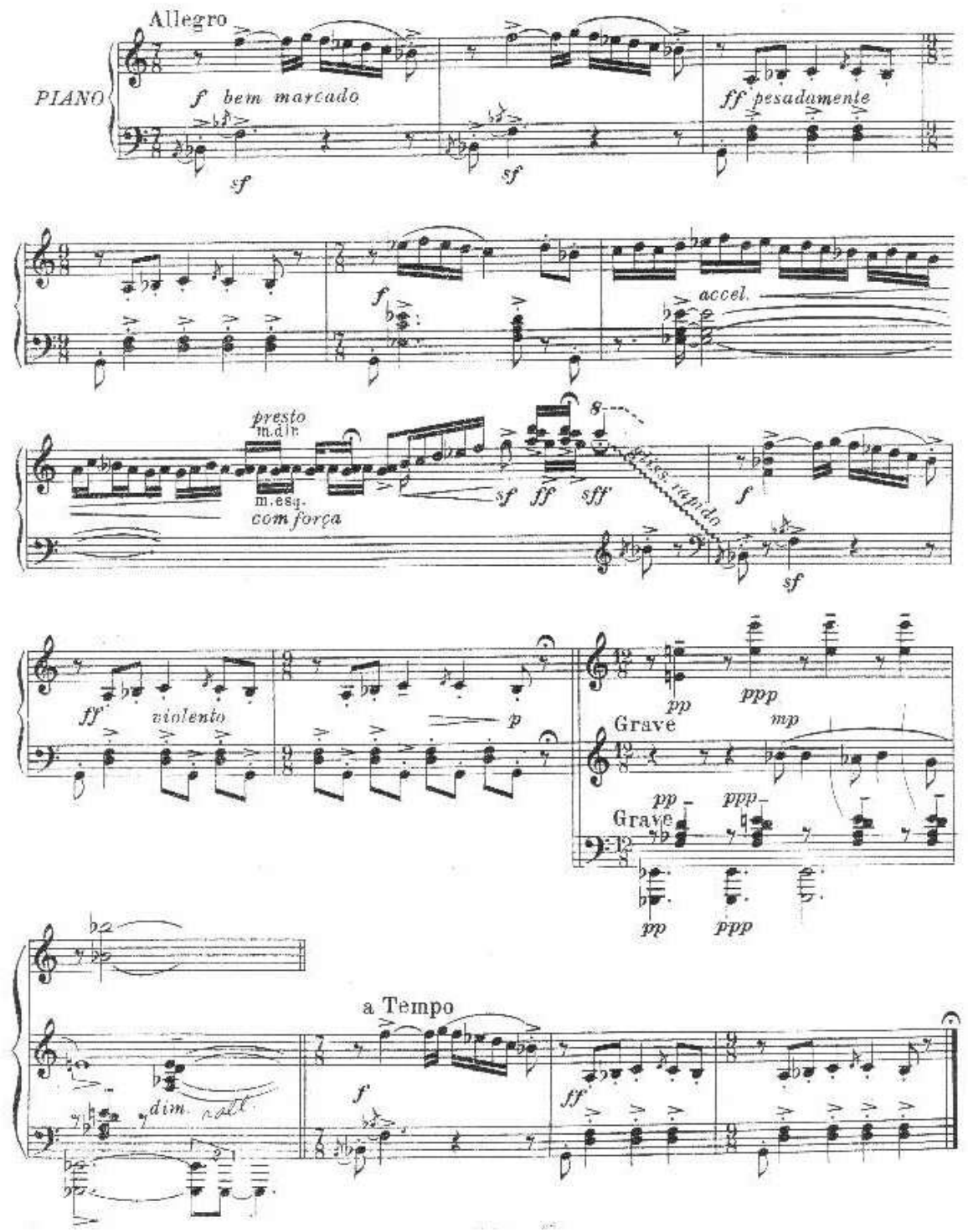

Entre os compositores rio-grandenses, nenhum teve até hoje maior projeção do que Radamés Gnattali (Porto Alegre, 1906 - Rio de Janeiro, 1988). As múltiplas vivências musicais, tanto no âmbito erudito como no popular, possibilitaram um caráter versátil e inovador à sua

${ }^{1}$ Fonte: ALBUQUERQUE, Armando (1926). 
obra. Para Béhague (1979, p. 210), "suas atividades na área popular têm sido úteis na sua busca por uma expressão nacionalista. Sua experiência direta com a música popular, no entanto, mesmo que comercial, proporcionou-lhe um conhecimento que poucos compositores nacionalistas brasileiros podem reivindicar". Foi também muito influente na forma de orquestração. A obra de Gnattali, além de conhecida no Brasil, ganhou projeção internacional, inclusive representando o país na New York World's Fair de 1939. Sobre a escolha, Mário de Andrade manifestou-se:

Tem uma habilidade extraordinária para manejar o conjunto orquestral, que faz soar com riqueza e estranho brilho. É certo que "jazzifica" um pouco demais para o meu gosto defensivamente nacional, mas apesar de sua mocidade, já domina a orquestra como raros entre nós. É a nossa maior promessa do momento (Andrade, 2006, p. 273).

Luiz Cosme (Porto Alegre, 1908 - Rio de Janeiro, 1965), que teve um período mais reduzido de atividade composicional do que os seus contemporâneos, revelou-se um compositor interessado na experimentação de múltiplas tendências. Entre 1930 e 1950 compôs música de caráter regional-nacionalista, utilizou-se de recursos modais e escreveu música dodecafônica. As melodias e os temas musicais riograndenses foram amplamente utilizados em sua obra. Em 1946 aproximou-se das ideias do Grupo Música Viva e começou a utilizar a técnica dodecafônica. Cosme teve sua obra amplamente divulgada em vida, na década de 1930 já era conhecido em Porto Alegre, no Rio de Janeiro e em São Paulo. Em 1937 as cidades de Paris e Berlim apreciariam suas composições (Mattos, 2005, p. 6).

Ao observar a obra de Natho Henn (Quaraí, 1901 - Porto Alegre, 1958), comparando-se à dos seus contemporâneos abordados, trata-se da menos conhecida atualmente. Há escasso material biográfico e 
poucos trabalhos sobre as composições, sendo algumas gravações de sua obra para piano. A obra de Natho Henn é estilisticamente romântica, essencialmente tonal, notável pelo aproveitamento de materiais da música folclórica rio-grandense. De acordo com Moritz, Henn:

[...] timbrou pelo amor à paisagem e aos costumes de sua querência, traduzindo os seus sentimentos em páginas tão singelas quanto expressivas pela forma e a linguagem. Não se pode dizer que tenha sido um folclorista, pois preenchendo o pentagrama com mãos pensativas e sensíveis, afirmou o complexo de sua personalidade. Das claves do seu subjetivismo emergiam fantasmas que amarguraram sua sensibilidade, embora docemente, e velaram seus pensamentos. O poeta que nele habitava encontrou as primeiras respostas à sua perplexidade em Chopin, Schumann, Schubert, em toda uma corte de músicos românticos. Esta afinidade eletiva e aproximação estilística, fatalmente determinaram influências que transitam em suas pequenas páginas pianísticas e vocais. Nem por isto ficaram à margem as forças imanentes de sentimentos nativos que constituíram, numa parcela significativa, o impulso de sua capacidade criadora (Moritz, 1974, p. 6).

\section{Um movimento articulado?}

Uma das questões centrais da ideia de modernismo no RS concentra-se na incorporação de elementos regionais à arte moderna. $O$ folclore, ao ser assimilado nas novas tendências da música erudita configuraria a essência da música composta no Brasil entre os anos delimitados nesta pesquisa. O romantismo europeu do século XIX empregou amplamente esse recurso, entretanto, o tratamento dado a esses elementos no Brasil a partir da segunda década do século XX foi outro. No caso brasileiro, a discussão em torno do uso de recursos da música folclórica baseou-se em objetivos claros: a construção de uma música nacional e a libertação dos modelos tradicionais europeus. $\mathrm{Na}$ música do RS percebe-se que a composição de caráter modernista seria um pouco posterior à Semana de Arte Moderna, e uma data significativa 
é 1926, ano das primeiras obras de Armando Albuquerque e de Radamés Gnattali, além das publicações da Revista Madrugada e da obra Coração Verde, do poeta Augusto Meyer, figura central do modernismo no estado. O movimento se estabeleceria com maior expressão através da literatura e da poesia, as quais tiveram influência decisiva, direta ou indiretamente, na composição modernista do estado. Dentre o material pesquisado, a revista Madrugada apresenta-se como fonte cultural importante. Produzida nos anos 1920, a Madrugada representa um retrato das transformações socioeconômicas e da vida cultural da cidade de Porto Alegre naquele período (Benetti, 2014, p. 79-82).

A partir da observação de obras dos compositores Armando Albuquerque, Natho Henn, Radamés Gnattali e Luiz Cosme, é possível marcar características peculiares da música produzida no RS da década de 1920 em diante, como a utilização de elementos da música folclórica regional, a absorção de tendências da vanguarda europeia e o alinhamento parcial às propostas modernistas brasileiras apresentadas na Semana de Arte Moderna. O período observado levou em consideração a atividade musical dos compositores no meio sul-riograndense. Entre os anos em que atuaram no estado, estabeleceram algum tipo de ligação. Se essas ligações configuram definitivamente um movimento, a exemplo do que aconteceu na música em São Paulo e no Rio de Janeiro, ainda não há argumentos suficientes para confirmar.

Os quatro compositores abordados nasceram na primeira década do século $X X$, e somente um deles não iniciou os estudos em música na cidade de Porto Alegre. Armando Albuquerque, Radamés Gnattali e Luiz Cosme formaram-se no Conservatório de Música do Instituto de Belas Artes do Rio Grande do Sul. Apesar da diferença de idade, os três estudaram no Conservatório na mesma época. Natho Henn, o único não nascido na capital, estudou música na capital uruguaia Montevidéu, mais perto em relação à distância entre Quarai e a capital do RS, cerca de seiscentos quilômetros. 
Fernando Mattos assinala uma situação que demonstra o convívio dos três compositores porto-alegrenses: os encontros que eram realizados na casa de José Pereira Cosme, pai de Luiz, dos quais o filho participava juntamente com Armando, Radamés, Augusto Meyer, entre outros (Mattos, 2005, p. 1). Além do contato evidente entre Gnattali, Cosme, Albuquerque e Meyer, os três compositores utilizaram textos do poeta para compor canções.

Radamés Gnattali e Luiz Cosme possuíam uma ligação evidente. Tocavam juntos desde o início da década de 1920, primeiramente animando filmes de cinema mudo, depois no Quarteto Henrique Oswald - Gnattali na viola e Cosme no violino. No ano de 1931 os dois realizariam uma apresentação na Sala Beethoven, em Porto Alegre, intitulada Noite Brasileira. O programa do concerto contava exclusivamente com obras dos dois compositores (Benetti, 2014, p. 134). Ainda em 1931, Radamés Gnattali fixaria residência no Rio de Janeiro; Luiz Cosme seguiu o mesmo caminho no ano seguinte.

Dias após a Noite Brasileira de Radamés Gnattali e Luiz Cosme, Simões aponta a realização de dois recitais de Natho Henn, também na Sala Beethoven. O primeiro, solo, e o segundo com o violinista Fernando Hermann (Simões, 2008, p. 85). Não há indicações sobre os repertórios apresentados, ficando a dúvida se havia alguma composição de Henn nos programas. Os escassos dados biográficos do compositor apontam que ele teria fixado residência em Porto Alegre somente no ano de 1942. No entanto, percebe-se que já atuava ao menos como intérprete no meio musical da capital.

Enquanto Gnattali, Cosme e Henn faziam-se presentes no meio musical da capital, Albuquerque não era conhecido. Apesar de ter escrito diversas obras inovadoras, com valor artístico, o seu nome não figura nos programas dos concertos. Foi ao Rio de Janeiro no ano de 1936, um período de pouco mais de dois anos em que se ausentou de Porto Alegre. Armando fez parte do grupo de orquestradores da Rádio 
Nacional juntamente com Radamés enquanto Cosme tocava na orquestra (Albuquerque, 1975, p. 9). Retornou ao RS em 1939.

Durante a década de 1940, somente Natho Henn e Armando Albuquerque residiam em Porto Alegre. Gnattali e Cosme já não mais atuavam diretamente no meio musical do estado. Apesar de não mais voltar a residir na capital, Cosme sempre utilizou elementos regionais na composição, sejam temas musicais, melodias, células rítmicas, estilos ou técnicas de condução melódica. Gnattali assumiria uma estética menos regional do que Cosme, mas também aproveitava temas folclóricos e outros elementos regionais, de acordo com a concepção do modernismo nacionalista.

Considerando as informações levantadas quanto à localização geográfica dos compositores ao longo dos anos delimitados para a pesquisa, pode-se definir que entre a década de 1920 e os primeiros anos da década posterior, se encontravam em Porto Alegre Armando Albuquerque, Radamés Gnattali e Luiz Cosme. Natho Henn figurou em alguns concertos, mas sua participação no meio da capital ainda carece de estudo aprofundado. De 1932 até 1936 ficaria somente Albuquerque. $\mathrm{Na}$ década de 1940, que compreende o período final da pesquisa, foi possível registrar a presença de Albuquerque e Henn. Não se encontrou, até agora, articulação entre os dois últimos, como um concerto, um convívio direto, ou qualquer outro tipo de registro relatando o contato. Sabe-se somente que Armando, anos após a morte de Henn, iniciou um trabalho de revisão da sua obra (Albuquerque, 1974).

Quantos às composições, um ponto em comum é o aproveitamento de elementos regionais. Existem algumas semelhanças que podem ser pontuadas entre um e outro compositor, mas cada um desenvolveu obras com características próprias. Gnattali, Cosme e Henn compunham, pelo menos na fase sul-rio-grandense, sob uma estética pós-romântica. Albuquerque foi o único cuja obra se propõe a afastar-se sistematicamente do sistema tonal. O elemento regional aparece de 
forma distinta, diretamente pela utilização de textos de poetas do RS, indiretamente pela maneira como Armando ilustra e representa as suas ideias musicais. Pelo aspecto inovador de sua obra, não é possível observar um alinhamento à estética nacionalista. Com base nisso podemos afirmar que é, entre os quatro, o mais representativo compositor de vanguarda da primeira metade do século XX no RS.

Os elementos externos, sejam as tendências europeias ou o modernismo brasileiro, ao entrarem na composição do estado, integraram-se com os elementos da música folclórica, produzindo uma nova música erudita. Ainda não há como afirmar se os compositores sulrio-grandenses do período de fato constituíram um movimento modernista estruturado mas, conforme apontado, há algumas interrelações a considerar.

\section{Referências:}

ALBUQUeRQUE, A. A obra musical de Natho Henn. Porto Alegre: Movimento, 1974.

. Canções sobre versos de Augusto Meyer e Athos Damasceno. Porto Alegre: Movimento, 1975.

ANDRADE, M. Música, doce música. 3. ed. Belo Horizonte: Itatiaia, 2006.

BÉHAGUE, G. Music in Latin America: An Introduction. New Jersey: Prentice-Hall, 1979.

BENETTI, G. F. O modernismo musical no Rio Grande do Sul (1926-1945): Regionalismos, continuidades e rupturas. Saarbrücken: Novas Edições Acadêmicas, 2014.

CORTE REAL, A. T. Subsídios para a história da música no Rio Grande do Sul. Porto Alegre: UFRGS, 1980.

FERREIRA, A. D. Palco, salão e picadeiro: em Pôrto Alegre no século XIX. Porto Alegre: Ed. Globo, 1956.

MARIZ, V. História da música no Brasil. 6. ed. Rio de Janeiro: Nova Fronteira, 2005. 
MATTOS, F. L. Estética e música na obra de Luiz Cosme. 2005. 336 f. Tese (Doutorado em Música)-Instituto de Artes, Universidade Federal do Rio Grande do Sul, Porto Alegre, 2005.

MORITZ, P. A. Apresentação. In: ALBUQUERQUE, Armando. A obra musical de Natho Henn. Porto Alegre: Movimento, 1974. p. 6.

NOGUEIRA, I. P. El pianismo en la ciudad de Pelotas (RS, Brasil) de 1918 a 1968. Pelotas: Editora Universitária, 2003.

; SOUZA, M. A música (1889-1930). In: BOEIRA, N.; GOLIN, T. (Org.). História Geral do Rio Grande do Sul. v. 3, n. 2. Passo Fundo: Méritos, 2007. p. 329-357.

SIMÕES, J. R. A sala Beethoven (1931-1932): música e cultura em Porto Alegre. 2008. 116 f. Trabalho de Conclusão de Curso (Graduação em História)-Faculdade de Filosofia e Ciências Humanas, Pontifícia Universidade Católica do Rio Grande do Sul, Porto Alegre, 2008. 